\title{
Dossiê
}

Partidos políticos, eleições e comportamento político-eleitoral no Brasil

\section{Votos brancos e nulos no Brasil: bases cognitivas e atitudinais}

\author{
Rafael da Silva \\ Professor da Universidade Estadual de Maringá \\ eu_fael@yahoo.com.br.
}

Éder Rodrigo Gimenes

Doutorando do Programa de Pós-Graduação em Sociologia Política da UFSC eder.mestrado@gmail.com

Julian Borba

Professor da Universidade Federal de Santa Catarina borbajulian@yahoo.com.br

\section{Ednaldo A. Ribeiro}

Professor da Universidade Estadual de Maringá e do Programa de Pós-Graduação em Ciência Política da UFPR ednaldorip@uol.com.br

Resumo: Qual o significado dos votos brancos e nulos nas eleições brasileiras? Alguns estudos apontaram que tais modalidades de voto, juntamente com as abstenções, seriam uma expressão de protesto, denotando que os eleitores depositariam baixa credibilidade no processo político formal. De outro lado, há ainda pesquisadores que interpretam tais votos como relacionados à falta de sofisticação política do eleitorado. Com base em dados do LAPOP de 2010, analisamos as relações entre votos brancos e nulos e a sofisticação política dos eleitores, a confiança em instituições representativas e no processo eleitoral, e com o descontentamento com a situação econômica pessoal e do país.

Palavras-chave: Comparecimento eleitoral; Votos brancos; Votos nulos; Protesto.

Abstract: What is the meaning of blank and null votes in Brazilian elections? Some studies have indicated that such modalities of voting, together with the abstentions, would be an expression of protest, showing that voters would deposit low credibility in the formal political process. On the other hand, there are still researchers who interpret such votes as related to political sophistication of the electorate. Based on data from the 2010 LAPOP, we 
analyze the relationships between blank and null votes and political sophistication, trust in representative institutions and the electoral process and discontentment with individual and national economic situation in Brazil.

Keywords: Voter turnout; White votes; Null votes; Protest.

\section{Introdução}

Por ser a característica mais elementar de um regime democrático representativo, a eleição assume centralidade na relação entre o eleitorado e o sistema político, fato este que a tornou um tema amplamente estudado em seus diversos enfoques e nas diversas áreas das Ciências Sociais e aplicadas. Os principais estudos sobre eleições se concentraram em alguns aspectos específicos, como o comportamento do eleitor, construindo modelos de comportamento eleitoral (Berelson, Lazarsfeld e MacPhee, 1954; Downs, 1957; Campbell et al, 1960).

No caso brasileiro, com a redemocratização, houve um vertiginoso crescimento destes estudos visando decodificar a participação do eleitor nesse novo momento da política nacional. Porém, um aspecto da participação eleitoral, já estudado em momentos pretéritos através do conceito de "alienação eleitoral" (Santos, 1987), continuou sendo pouco abordado: o voto branco e nulo.

No tocante à participação eleitoral manifesta através dessas duas modalidades de voto, há uma divergência na literatura especializada quanto aos seus significados. De um lado, temos autores favoráveis à tese dos votos brancos e nulos como expressão de protesto e de descontentamento do eleitor (Santos, 1987; Borba, 2008). De outro, há pesquisadores que defendem que esses votos são reflexos da baixa sofisticação política do eleitorado, que se materializaria, em parte, nas dificuldades cognitivas para operar de maneira correta a urna eletrônica (Nicolau, 2003; 2004).

Nesse sentido, o objetivo central deste artigo reside na iniciativa de compreender os significados dos votos brancos e nulos no que tange à divergência acima mencionada, propondo responder as seguintes indagações: Seria esse comportamento resultado da baixa sofisticação de parcela do eleitorado, que não consegue operacionalizar seus votos na urna eletrônica? Seriam esses votos expressões de protesto de eleitores que nutrem algum descontentamento, seja com a economia ou com o sistema político e suas instituições? Ou ainda, sintetizando as duas proposições acima, seriam esses votos 
uma forma que eleitores de baixa sofisticação encontraram para expressar a sua insatisfação com a economia e a política?

Para responder a essas questões, o artigo está organizado da seguinte maneira: além desta introdução, apresentamos uma breve revisão da literatura sobre o tema, seguida de seção voltada à exposição metodológica e outra na qual são apresentados os resultados dos testes realizados. Por fim, nas considerações finais, discutimos sobre os principais achados e alguns desdobramentos em termos de uma agenda de pesquisas sobre o tema.

\section{O debate sobre as causas do voto branco e nulo}

Um dos primeiros esforços ${ }^{1}$ de compreensão dos votos brancos e nulos no Brasil está em Santos (1987), que cunhou o termo "alienação eleitoral" como o fenômeno comportamental que reúne em um só conceito o voto branco, o nulo e a abstenção. Analisando o período de 1945 a 1982, o autor afirmou que "quanto maior a incerteza do significado político efetivo do processo eleitoral, menor o retorno esperado e maior a taxa de alienação" (p. 55). Assim, a alienação, na concepção do autor, seria uma forma de o eleitor expressar sua insatisfação com o ambiente político de incerteza, sendo uma forma de protesto. ${ }^{2}$

A primeira objeção a essa abordagem surgiu nos anos seguintes à sua publicação e centrava-se principalmente no procedimento de aglutinação em um único fenômeno, a alienação, de distintos comportamentos do eleitorado (os votos brancos e nulos e as abstenções), para os quais se estabeleceu uma mesma base causal (Lima Júnior, 1990; 1993). Segundo o autor,

Pode-se objetar, no entanto, que a interpretação do comportamento eleitoral alienado, na medida em que agrega manifestações eleitorais diferentes, esteja equivocada do ponto de vista dos fatores determinantes da alienação. Ou, simplesmente: 0 que leva o eleitor a se abster não é exatamente o que leva o eleitor a votar em branco ou a anular o voto (Lima Júnior, 1990, paginação irregular).

1 Vale mencionar que Schwartzman $(1975 ; 1988)$ abordou o tema de forma secundária, nos últimos capítulos das obras referenciadas. Porém, foi com Santos (1987) que o tema ganhou notoriedade.

2 Segundo Santos (1987), a eleição para a Câmara Federal em 1970 atingiu percentual de 53\% de alienação eleitoral. 
Para Lima Júnior (1990; 1993), as bases das abstenções são distintas das dos votos brancos e nulos, uma vez que barreiras de ordem ecológica incidem sobre aquelas, aumentando os custos de comparecer à urna no dia da votação. Já para os votos brancos e nulos, as barreiras seriam de caráter social, principalmente o nível de escolaridade. Tais conclusões foram referendadas parcialmente por Costa (2007), que evidenciou tais preditores, os ecológicos e sociais, como importantes, porém não suficientes para compreender os fenômenos em questão.

Os estudos de Jairo Nicolau (2003; 2004) problematizam os votos brancos e nulos e defendem a tese de que, principalmente os votos nulos, devem ser compreendidos como resultado da baixa sofisticação do eleitorado, especialmente no aspecto da escolaridade. Para o autor, isso fica evidente ao comparar as taxas de votos nulos antes e depois da instauração da urna eletrônica, quando se verifica uma queda substancial. Ainda segundo o autor, a cédula eleitoral, uma das mais difíceis de manusear, fazia com que muitos votos fossem anulados por erro na escrita do número ou nome do candidato. Já com a implantação da urna eletrônica, esse percentual diminuiu, mas a baixa sofisticação continua sendo um fator causador das anulações, fazendo com que os eleitores pouco familiarizados com a tecnologia errem na digitação do número do candidato, anulando, por consequência, o voto.

O estudo de Borba (2008), ao analisar a eleição presidencial de 2002 com base na pesquisa ESEB daquele ano, identificou que os eleitores que haviam votado em branco ou nulo no referido pleito nutriam considerável nível de insatisfação com o funcionamento das instituições políticas, baixa adesão específica à democracia, conforme as dimensões apontadas por Easton (1975), e manifestavam baixo sentimento de eficácia política. Silva (2013) matizou esta tese, na medida em que encontrou associação entre o voto nulo e baixos indicadores educacionais.

O que nenhum dos trabalhos acima analisou foi o efeito das variáveis relacionadas à avaliação da economia sobre as dimensões do comparecimento e dos votos brancos e nulos. Em que pese a existência de expressiva literatura internacional sobre o chamado "voto econômico" (Kiewiet, 1983; Lewis-Beck, 1988; Kinder, Adams e Gronke, 1989; Duch, 2001) e seu impacto principalmente no plano do comparecimento eleitoral (Downs, 1957; Aldrich, 1993), tais análises ainda não foram devidamente incorporadas ao estudo do tema da alienação eleitoral no Brasil. 
Dessa maneira, objetivando sanar lacunas na literatura, versamos sobre os efeitos das distintas abordagens anteriormente mencionadas sobre a explicação dos votos brancos e nulos no Brasil. Mais diretamente, a intenção é avaliar a pertinência de duas hipóteses fundamentais: a do protesto e a da baixa cognição.

\section{Metodologia e hipóteses}

Os dados utilizados neste trabalho são oriundos do Barômetro da Américas - 2010, pesquisa capitaneada pelo Latin American Public Opinion Project (LAPOP), do qual selecionamos a etapa brasileira. A coleta de dados ocorreu entre os meses de março e abril do ano de 2010, através de uma amostra probabilística, quando foram entrevistados 2.482 eleitores, com margem de erro de 1,79\%. ${ }^{3}$

No momento da coleta de dados, o quadro eleitoral brasileiro não estava definido, sendo que entraria em vigor apenas no mês de agosto o Horário Gratuito da Propaganda Eleitoral (HGPE), fator fundamental no processo de definição das escolhas eleitorais. Desta maneira, observamos uma diferença entre o dado oficial de votos brancos e nulos de 9\%, divulgado pelo Tribunal Superior Eleitoral (TSE), e o percentual identificado pelo LAPOP, de 15\%. ${ }^{4}$

Para além dessa discrepância, é importante discutir de forma mais detalhada a limitação apontada na introdução, imposta pela natureza dos dados utilizados. A variável sobre o voto branco e nulo não se refere diretamente a um comportamento praticado pelo respondente em um passado recente, mas à manifestação de uma intenção futura que pode ser alterada em razão dos eventos de campanha, uma vez que a coleta de dados do LAPOP ocorreu antes das eleições de 2010. Essa característica dos dados é ainda mais problemática diante do desejo de testar a hipótese da baixa cognição como propulsora desse tipo de voto, já que os potenciais erros que poderiam conduzir a anulação não intencional obviamente não podem ser captados antes da sua ocorrência.

Essas limitações impõem sérias restrições ao teste dessa hipótese em específico. Todavia, a presença de variáveis relacionadas ao protesto político torna o LAPOP ainda a

3 Mais informações: http://www.vanderbilt.edu/lapop/ab2010/AB-2010-Tech-Info-070213-W.pdf. 4 A pesquisa ESEB foi realizada no mês seguinte às eleições (novembro) e registrou um percentual de votos brancos e nulos de 3,5\%. Já o Latinobarómetro foi realizado nos meses de setembro e outubro, quando a campanha eleitoral estava em sua reta final, porém a pergunta foi direcionada ao partido no qual o eleitor votaria. 
melhor opção. É importante destacar que um desenho de pesquisa experimental que simulasse situações de escolha semelhantes àquelas que ocorrem nos pleitos oficiais poderia indicar de maneira adequada quais os efeitos tanto da insatisfação e do descontentamento quanto da dificuldade em lidar com a urna eletrônica.

Definida a base, o passo seguinte foi selecionar as variáveis específicas que materializariam as três dimensões de preditores: socioeconômicos, de confiança nas instituições políticas e no processo eleitoral e de avaliação da economia. No âmbito socioeconômico, foram selecionadas as seguintes variáveis: sexo (binária, 1-homem e 0 mulher), idade (total de anos de vida, com escala de 18 a 89 anos) e escolaridade (total de anos de estudo, com escala de 0 a 17 anos), esta última visando testar a tese da baixa sofisticação.

Quanto às variáveis atitudinais, foram escolhidos o Índice de Confiança Institucional (índice somatório de confiança no Congresso, nos partidos políticos, na Justiça e no Governo Federal, com escala de 4 a 28 pontos) e de Confiança no processo eleitoral (escala de 1 a 7 pontos). ${ }^{5}$

No tocante à economia, desde os estudos clássicos sobre o voto econômico na década de 1970 (Kramer, 1971; Tufte, 1978), considera-se o entendimento de que a economia interfere na decisão do eleitor, que tende a votar no incumbente se julgar que a economia está funcionando de maneira satisfatória. Numa tentativa de diálogo desse aspecto para explicar a participação do eleitor via voto branco/nulo, seguiu-se a pista de Kindler e Kiewiet (1981), que buscaram no âmbito individual a avaliação dos eleitores acerca da saúde da economia por meio de duas medidas de avaliação, a pessoal e a sociotrópica ${ }^{6}$ retrospectiva. Assim, para a análise que seguirá, criou-se uma única medida, o Índice de Avaliação da Economia, formado pela soma das avaliações retrospectivas da economia: pessoal e sociotrópica (escala de 2 a 10 pontos).

Os dados foram analisados através de modelos de regressão logística binária, modalidade multivariada, mais apropriada para o tratamento desse tipo de dados. Como forma de testar as dimensões tradicionalmente abordadas pela literatura como determinantes dos votos brancos e nulos, foram construídos dois modelos de regressão: o

5 Informações detalhadas sobre as variáveis constam no Apêndice Metodológico, no final do texto.

6 A avaliação sociotrópica é a avaliação que o(a) eleitor(a) faz da saúde econômica do país. As avaliações aqui utilizadas e condensadas em uma única métrica são: a do país, sociotrópica, e a pessoal, ambas considerando os últimos 12 meses, retrospectiva, período de referência da pesquisa. 
primeiro tomou como variável dependente o próprio voto, classificando em distintas categorias os eleitores que declararam intenção de voto em algum candidato à presidência da República e aqueles que informaram que pretendiam votar em branco ou anular seu voto. Tal modelo foi construído com a pretensão de verificar se e em que medida tais modalidades de voto se relacionam a aspectos cognitivos do eleitor, às dimensões concernentes à confiança nas instituições políticas democráticas e no próprio processo eleitoral e à avaliação da situação econômica pessoal e do país. Já o segundo tomou as mesmas variáveis independentes para a tentativa de identificação de preditores da variável referente à participação em movimentos de protesto.

O uso dessas distintas variáveis dependentes teve como objetivo verificar algumas questões problematizadas pela literatura. Se o voto branco e nulo está relacionado ao "retorno esperado do voto" (Santos, 1987), logo, é de esperar que os eleitores que confiam menos nas instituições democráticas e/ou no processo eleitoral são os que estão dispostos a anular ou votar em branco.

O mesmo vale para a dimensão da avaliação da economia, de modo que, considerando a máxima de que o eleitor vota com o "bolso", os mais insatisfeitos com sua situação econômica ou com a economia do país seriam os que menos votariam nominalmente, desde que não verificassem na oposição uma alternativa clara de solução para os problemas econômicos?

Já entre as variáveis sociodemográficas, seria de esperar que, sendo o voto uma atividade de baixo custo para o eleitor, sua distribuição fosse relativamente igual entre as diferentes escalas de escolaridade. Porém, as exigências cognitivas para operação da urna eletrônica fariam com que os eleitores menos escolarizados tivessem maior chance de votar em branco ou anular seu voto em comparação com os mais escolarizados.

Por fim, a literatura internacional tem identificado uma distribuição relativamente desigual na participação eleitoral de homens e mulheres, com sobrerepresentação dos primeiros em distintas modalidades de participação, incluído o comparecimento eleitoral (Verba, Schlozman e Brady, 1995). Da mesma maneira, com relação à idade, tem-se verificado que a participação eleitoral aumenta com a elevação dos anos de vida do eleitor, o que também se verifica em outras modalidades convencionais de participação

7 Anderson (2000) afirmou que variáveis de contexto filtram a influência da economia nas eleições, dentre elas o fato de ter um projeto alternativo claro ao da situação. 
política, configurando assim uma distinção geracional no comportamento político (Miller e Shanks, 1996; Lyons e Alexander, 2000; Dalton, 2013). Logo, seria de esperar maior votação nominal entre os homens e os mais velhos.

\section{Análise dos dados}

Antes de iniciar a análise dos dados, cabe contextualizar a dimensão que os votos brancos e nulos têm assumido na dinâmica do processo eleitoral brasileiro recente. Conforme o gráfico 1 aponta, essa modalidade de participação eleitoral tem sido constante desde a retomada das eleições diretas para presidente em 1989. Houve dois momentos, 1994 e 1998, em que os percentuais deram um salto, porém, com a implantação, em 1996, ${ }^{8}$ e universalização da urna eletrônica, esses percentuais caíram. Conforme observou Nicolau (2003; 2004), com a urna eletrônica os votos brancos e nulos caíram substancialmente, o que revela a complexidade do antigo processo que envolvia cédulas e no qual os votantes tinham que escrever o nome ou o número dos seus candidatos, abrindo uma margem grande para a ocorrência de erros no preenchimento, fato que se agrava quando se observa o baixo nível educacional do eleitor médio. Com o voto eletrônico, houve uma diminuição e estabilização do quadro: os votos nulos oscilaram entre 6\% e 5\%, com o menor percentual para os momentos de segundo turno, e os votos em branco ficaram em 3\%, com exceção do segundo turno de 2006 que registrou 1\%. Esses valores estão próximos das eleições de 1989, primeira eleição direta para presidente após o fim da ditadura, quando foi esperado um incremento na participação, já que o país viveu, no período antecedente, um interregno ditatorial.

8 Conforme o TSE, a urna foi implantada em mais 50 municípios nas eleições municipais de 1996. 
Gráfico 1: Voto branco e nulo nas eleições presidenciais (1989-2010)

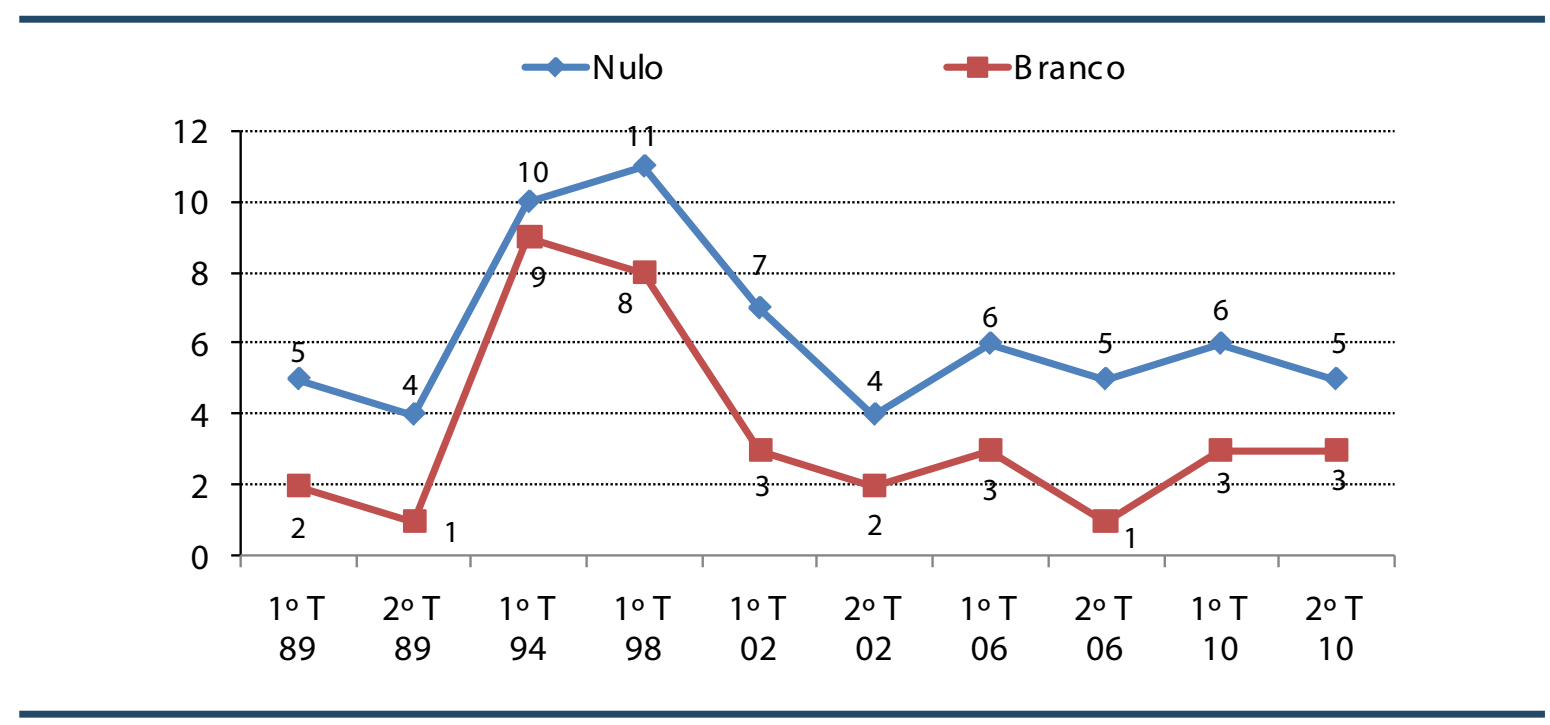

Fontes: Dados eleitorais brasileiros (1982-2006) e TSE. Elaboração dos autores.

Feita a contextualização, parte-se agora para a compreensão dos significados dos votos brancos e nulos. Conforme dito acima, o procedimento analítico adotado foi o de construir um modelo de regressão logística, incorporando um conjunto de variáveis independentes relacionadas às dimensões explicativas identificadas na literatura sobre o não voto. Nesse sentido, as variáveis que compõem o modelo de regressão abaixo contribuem para a tentativa de verificar a influência da baixa sofisticação dos eleitores com relação à operacionalização da urna eletrônica, da pouca confiança em instituições representativas e no processo eleitoral no Brasil, do descontentamento com a situação econômica pessoal e do país. Além dessas variáveis, sexo e idade foram acrescentados ao modelo como controles.

Tabela 1. Preditores dos votos brancos/nulos

\begin{tabular}{ll}
\hline Preditores & Exp/B (S.E.) \\
\hline Sexo & $1,135(, 147)$ \\
\hline Idade & $0,983^{*}(, 005)$ \\
\hline Escolaridade & $1,021(, 021)$ \\
\hline Índice de Confiança Institucional & $0,968^{* *}(, 014)$ \\
\hline Confiança no processo eleitoral & $0,825^{*}(, 042)$ \\
\hline Índice de Avaliação da Economia & $0,826^{*}(, 050)$ \\
\hline Constante & $2,795(, 445)$ \\
\hline \% de acertos do modelo: 85,4 & \\
\hline Sig. $0,000 . *$ Sig. $0,010-0,050$. & \\
\hline
\end{tabular}


Iniciando pela análise das variáveis de controle, verifica-se que o sexo dos indivíduos, tendo a categoria "masculino" como referência, não é significativo para a predição do voto não nominal, o que significa afirmar que ser homem ou mulher não faz diferença para a escolha entre votar em algum candidato ou anular/votar em branco.

Com relação à idade, o efeito é significativo e negativo, de modo que quanto maior o número de anos de vida do indivíduo, menor a probabilidade de que seu voto seja branco ou nulo, reduzindo as chances em 1,7\% a cada ano de idade. Nesse sentido, o resultado coaduna com os argumentos de autores como Dalton (2013), que afirma que a inserção na vida adulta (por conta de alterações como a condição de estudante a trabalhador e a constituição de família) está relacionada a repertórios de participação política convencionais. Ainda que a variável se relacione ao comparecimento eleitoral, o entendimento é de que o maior envolvimento em meios tradicionais de engajamento político interfere, em alguma medida, na decisão do voto.

A ausência de efeito estatisticamente significativo da escolaridade sobre o voto não nominal não permite a confirmação da tese de que essa modalidade de participação eleitoral seja fruto da baixa cognição do eleitor (Nicolau, 2003; 2004), já que o resultado indica que esse comportamento se distribui de forma aleatória entre os diferentes níveis de escolarização. Conforme destacamos anteriormente, contudo, esse resultado deve ser relativizado em razão da variável dependente se referir a uma intenção de votar em branco ou nulo e não ao comportamento efetivo. Neste sentido, o que se identifica é que a escolaridade não afeta a intenção de votar dessa maneira, pois as dificuldades e o erro provocados pela baixa escolaridade no momento da operação da urna eletrônica não podem ser captados.

No que diz respeito às variáveis que mensuram a antinomia contentamento/descontentamento dos brasileiros com questões relacionadas à política e a economia, verificou-se que as medidas de confiança nas instituições representativas e no processo eleitoral se revelaram preditoras dos votos brancos e nulos. Os resultados indicam uma relação inversa entre a escala de confiança nas instituições políticas e a chance de votar em branco ou nulo, já que elevações na confiança diminuem em 3,2\% a probabilidade na ocorrência desses tipos de votos. Algo similar acontece com a confiança no funcionamento do processo eleitoral como um todo, na medida em que cada nível adicional de confiança reduz em 17,5\% a chance de o eleitor votar em branco ou anular seu voto. 
Tais resultados são semelhantes para as medidas de avaliação da economia, tanto pessoal quanto sociotrópica. A relação destas variáveis com o voto não nominal também é inversa e significativa em nível exigente, como aconteceu com as variáveis independentes anteriores. A identificação do efeito negativo desta percepção sobre o voto nos permite inferir que quanto pior é a interpretação dos eleitores sobre a situação econômica do país e sua situação pessoal, maior é a chance de que seus votos sejam anulados ou em branco, sendo que cada ponto de redução na escala de avaliação econômica implica aumento de 17,4\% de chance de voto não nominal.

Diante dos efeitos verificados no modelo acima, identificou-se que a decisão do voto branco ou nulo é influenciada pelo descontentamento dos brasileiros com o funcionamento das instituições democráticas representativas, com o sistema eleitoral e com a situação econômica do país, o que permite rumar em direção à tese de que essa modalidade de participação eleitoral seria, em alguma medida, expressão de protesto.

Nesse sentido, diante da relação entre votos brancos e nulos e descontentamento, pode-se conjecturar que, para esses eleitores, diante do quadro político-econômico que se apresenta, a melhor opção, para utilizar uma expressão de Hirshmann (1973), é a "saída", ou seja, optar por nada que se relacione ao sistema vigente e, desta maneira, anular o voto ou votar em branco. Assim, a tese do voto nulo como resultado de eleitores de baixa sofisticação, no contexto deste trabalho, não foi corroborada. ${ }^{9}$

Considerado os resultados acima, surgem questões adicionais em relação aos votos brancos e nulos e ao protesto: Se esses votos são expressões das insatisfações dos eleitores, que veem no voto branco ou nulo uma maneira de protestar, teria o ato efetivo de protestar, por meio da adesão a manifestações, por exemplo, a mesma base causal que os votos brancos e nulos? Ou estes repertórios de protestos obedeceriam a outra lógica causal?

O LAPOP 2010 permite fazer a verificação empírica dessa questão, pois conta com uma pergunta sobre o envolvimento efetivo em manifestações e protestos, qual seja: "Nos últimos doze meses você participou de alguma manifestação ou protesto público?". Utilizou-se o mesmo procedimento adotado e as mesmas variáveis independentes para analisar os votos brancos/nulos.

9 Vale lembrar que se operacionalizou metodologicamente agregando em uma única variável dependente o voto branco e nulo. 
Tabela 2. Preditores do protesto

\begin{tabular}{ll}
\hline Preditores & Exp/B (S.E.) \\
\hline Sexo & $1,421(, 187)$ \\
\hline Idade & $0,994(, 007)$ \\
\hline Escolaridade & $1,144^{*}(, 028)$ \\
\hline Índice de Confiança Institucional & $1,001(, 018)$ \\
\hline Confiança no processo eleitoral & $1,011(, 050)$ \\
\hline Índice de Avaliação da Economia & $0,882^{* *}(, 066)$ \\
\hline Constante & $0,039(, 575)$ \\
\hline$\%$ de acertos do modelo: 94,2 & \\
\hline$*$ Sig. $0,000 * *$ Sig. Entre 0,050 e 0,060 & \\
\hline
\end{tabular}

Fonte: LAPOP, 2010.

O modelo apresentado acima permite inferir que o voto não nominal (branco ou nulo) e o protesto possuem preditores distintos, ao menos no que tange ao conjunto de variáveis componentes dos modelos. O dado mais significativo deste modelo é que somente a variável escolaridade se mostrou estatisticamente significativa, num nível bastante exigente (sig. 0,000) e com efeitos acumulados bastante expressivos, o que permite inferir que indivíduos com maiores recursos individuais, neste caso especialmente maior escolarização, são mais propensos à contestação.10 Entre os brasileiros, verifica-se que a elevação de cada ano de estudo contribui em 14,4\% para o aumento da propensão de o cidadão se envolver em atividades não convencionais. Tal resultado corrobora aquele identificado por Borba, Ribeiro e Gimenes (2013) entre o eleitorado brasileiro, os quais afirmam que o fato de o protesto ser uma ação política utilizada por indivíduos com alta mobilização cognitiva nos permite tratá-lo como um repertório de ação política utilizado por eleitores portadores de recursos, como destaca Opp (2009).

As demais variáveis, relacionadas a outras dimensões sociodemográficas (sexo e idade) e atitudinais (avaliação da economia e confiança nas instituições e no processo eleitoral), não se mostraram estatisticamente significativas. Dessa forma, verifica-se que o protesto é a opção dos segmentos mais escolarizados do eleitorado brasileiro.

Tomados em comparação, os dois modelos propostos revelam bases distintas para os fenômenos em questão. Enquanto os votos brancos e nulos possuem um claro

10 Para a América Latina, Ribeiro \& Borba (2010 e 2014, no prelo) apontaram a escolaridade como principal variável explicativa em relação ao fenômeno do protesto, enquanto seus resultados demonstraram que a escala de pós-materialismo não teve o mesmo comportamento (Ribeiro \& Borba, 2010a). 
T\&P Rafael da Silva

Éder Rodrigo Gimenes

Julian Borba

Ednaldo A. Ribeiro

componente de insatisfação, que aqui associamos hipoteticamente ao protesto por meio do voto, o envolvimento em manifestações se apresenta fortemente relacionado à centralidade social do indivíduo. Mais do que estar descontente com o sistema político ou com o funcionamento da economia, o indivíduo que protesta é aquele possuidor de recursos educacionais que estão tradicionalmente relacionados à posse de recursos materiais de várias ordens.

\section{Considerações finais}

O conjunto das análises nos permitiu responder, ainda que de maneira provisória e parcial, as questões levantadas na introdução deste artigo. A tese do relacionamento da baixa sofisticação com o fenômeno do voto branco ou nulo não foi comprovada para o caso brasileiro, conforme atestam alguns estudos. De maneira alternativa, verificamos que estes votos são resultados do descontentamento com o funcionamento da democracia (aqui mensurado pela confiança em instituições representativas), com o processo eleitoral e com a economia.

De maneira complementar, identificamos que esse protesto específico e de natureza eleitoral, entretanto, possui bases distintas do comportamento de protesto geral, aqui expresso pelo envolvimento em manifestações. Enquanto no primeiro caso ficou nítido o papel da insatisfação, no segundo emergiu a dimensão dos recursos individuais, como já amplamente documentado (Verba; Schlozman \& Brady, 1995; Ribeiro \& Borba, 2014).

Ademais, verifica-se que os votos brancos e nulos e o ato de protestar por meio do envolvimento em manifestações não se constituem em repertórios do mesmo conjunto de brasileiros, já que seus preditores são distintos. Assim, os mais insatisfeitos, econômica e politicamente, tendem a não compactuar com alguma das ofertas no mercado eleitoral, optando pelo voto branco ou nulo. Já o protesto público é comportamento de cidadãos críticos, que expressam adesão à democracia e possuem um resíduo de insatisfação econômica. 


\section{Referências}

ALDRICH, J. Rational choice and turnout. American Journal of Political Science, 37, 1993, p. 246-278.

ANDERSON, C. J. Economic Voting and Political Context: a comparative perspective. Electoral Studies, n. 19, 2000, p. 151-170.

BERELSON, B. R.; LAZARSFELD, P.; MCPHEE, W. N. Voting a study of opinion formation in a presidential campaign. Chicago: Chicago University Press, 1954.

BORBA, J. As bases sociais e atitudinais da alienação eleitoral no Brasil. Revista Debates, v. 2, p. 134-157, 2008.

BORBA, J.; RIBEIRO, E. A.; GIMENES, E. R. Os apartidários brasileiros: bases sociais, atitudinais e comportamentais do eleitorado brasileiro. In: 7ํㅡㄹ Congreso Latinoamericano de Ciencia Política, 2013, Bogotá (Colômbia).

CAMPBELL, A.; CONVERSE, P. E.; MILLER, W. E.; STOKES, D. E. The American voter. New York: Wiley, 1960.

COSTA, H. de O. Democracia e representação política no Brasil: uma análise das eleições presidenciais (1989-2002). Porto Alegre: Sulina; Natal: UFRN, 2007.

DALTON, R. J. The apartisan American: dealignment and changing electoral politics. Washington, DC: Sage, 2013.

DOWNS, A. An Economic Theory of Democracy. New York: Harper\&Row, 1957.

DUCH, R. M. A developmental model of heterogeneous economic voting in new democracies. American Political Science Review, 95 (4), 2001, p. 895-910.

EASTON, D. A re-assessment of the concept of political support. British Journal of Political Science, Cambridge, v. 5, n. 4, 1975, p. 435-457.

HIRCHMANN, A. Saída, voz e lealdade: reações ao declínio de firmas, organizações e estados. São Paulo: Editora Perspectiva AS, 1973.

KIEWIET, D. R. Macroeconomics and microeconomics: the electoral effects of economic issues. Chicago: University of Chicago Press, 1983.

KINDER, D. R., KIEWIET, D. R. Sociotropic politics: the American case. British Journal of Political Science, v. 11, n. 2, 1981, p. 129-161.

; ADAMS, G.; GRONKE, P.W. Economics and politics in the 1984 Amwrican presidential election. In: American Journal of Political Science, 33, 1989, p. 491-515. 
T\&P Rafael da Silva

Éder Rodrigo Gimenes

Julian Borba

Ednaldo A. Ribeiro

KRAMER, G. H. Short-Term Fluctuations in U. S. Voting Behavior. APSR. V. LXV, n. 1. Mar: 131-143, 1971.

LAPOP. Latin American Public Opinion Project, 2010.

LEWIS-BECK, M. Economics and Elections: the major western democracies. Ann Arbor: University of Michigan Press, 1988.

LIMA JÚNIOR, O. B. Democracia e instituições políticas no Brasil dos anos 80. São Paulo: Loyola, 1993.

A alienação eleitoral e seus determinantes. In: Revista Brasileira de Ciências Sociais, n. 14, ano 5, 1990.

LYONS, W., ALEXANDER, R. Tale of two electorates. In: Journal of Politics, 62, 2000, p. 1014-34.

MILLER, W.E.; SHANKS, M.J. New American Voter. Cambridge: Harvard University Press, 1996.

NICOLAU, J. A participação eleitoral: evidências sobre o caso brasileiro. Coimbra, VIII Congresso Luso-Afro-Brasileiro de Ciências Sociais. 2004.

A participação eleitoral no Brasil. In: VIANA, L. W. A democracia e os três poderes no Brasil. Belo Horizonte: Ed. UFMG, 2003.

OPP, K. D. Theories of political protest and social movements: a multidisciplinary introduction, crítique, and synthesis. Londres: Routledge, 2009.

RIBEIRO, E. A.; BORBA, J. Participação política na América Latina. Maringá: Eduem, 2014 (no prelo).

- Participação e pós-materialismo na América Latina. In: Revista Opinião Pública, Campinas, v. 16, p. 28-63, jun. 2010.

. Protesto político na América Latina: tendências recentes e determinantes individuais.

Caxambú: 35 Encontro Anual da ANPOCS, 2010a.

SANTOS, W. G. Crise e castigo: partidos e generais na política brasileira. Rio de Janeiro: Editora Vértice/IUPERJ, 1987.

SCHWARTZMAN, S. São Paulo e o Estado Nacional. São Paulo: DIFEL, 1975.

Bases do autoritarismo brasileiro. Rio de Janeiro: Campus, 1988.

SILVA, Rafael da. Alienação eleitoral: um estudo comparado das bases sociais e atitudinais. In:

Revista Andina de Estudios Políticos. V. III, n. 1, 2013, p. 109-133.

TSE. Dados Eleitorais.

TUFTE, E. Political Control of the economy. Princeton: Princeton University Press, 1978.

VERBA, S.; SCHLOZMAN, K. L.; BRADY, H. E. Voice and equality: civic voluntarism in American politics. Cambridge: Harvard University, 1995. 


\section{Apêndice metodológico}

\section{Voto Branco/Nulo:}

[vb20] Se as próximas eleições presidenciais fossem nesta semana, em quem o(a) sr./sra. votaria?

$$
\begin{array}{ll}
\text { Codificação: } & 1=\text { Não votaria } \\
& \text { 2= Votaria no candidato ou partido do atual presidente } \\
3 & =\text { Votaria em algum candidato ou partido da oposição } \\
4 & =\text { Iria votar, mas votaria em branco ou nulo } \\
\text { Recodificação: } & 0=\text { Voto nominal [2 e 3]. } \\
& \text { 1= Voto branco ou nulo [4]. }
\end{array}
$$

\section{Protesto [2012]}

[prot3] Nos últimos 12 meses, participou de manifestação ou protesto público?

Codificação: $1=$ Sim, participou

$$
\text { 2= Não participou }
$$

Recodificação: $0=$ Não participou

$1=$ Participou

Sexo [2012]

[q1] Gênero

Codificação: 1= Homem

$$
\text { 2= Mulher }
$$

Recodificação: $0=$ Feminino

$1=$ Masculino

\section{Idade [2012]}

[q2] Qual a sua idade em anos completos?

Codificação: Aberta

Recodificação: Sem necessidade.

\section{Escolaridade}

[ed] Qual foi o último ano de educação que você completou ou foi aprovado? 
Codificação: Aberta.

Recodificação: Sem necessidade.

Índice de Confiança Institucional

[b10a] Até que ponto o(a) sr./sra. tem confiança na justiça?

[b13] Até que ponto o(a) sr./sra. tem confiança no Congresso Nacional?

[b14] Até que ponto o(a) sr./sra. tem confiança no Governo Federal?

[b21] Até que ponto o(a) sr./sra. tem confiança nos partidos políticos?

Codificação: $1=$ Nada.

$$
\begin{aligned}
& 2=2 \\
& 3=3 \\
& 4=4 \\
& 5=5 \\
& 6=6 \\
& 7=\text { Muito. }
\end{aligned}
$$

Recodificação: Sem necessidade.

O índice corresponde ao somatório das variáveis.

\section{Confiança no processo eleitoral}

[b47] Até que ponto o(a) sr./sra. tem confiança nas eleições?

Codificação: $1=$ Nada.

$$
\begin{aligned}
& 2=2 \\
& 3=3 \\
& 4=4 \\
& 5=5 \\
& 6=6 \\
& 7=\text { Muito. }
\end{aligned}
$$

Recodificação: Sem necessidade.

\section{Índice de avaliação da economia}

[idio1] Como o(a) sr./sra. avalia, em geral, sua situação econômica?

[soct1] Como o sr./sra. avalia a situação econômica do país? 


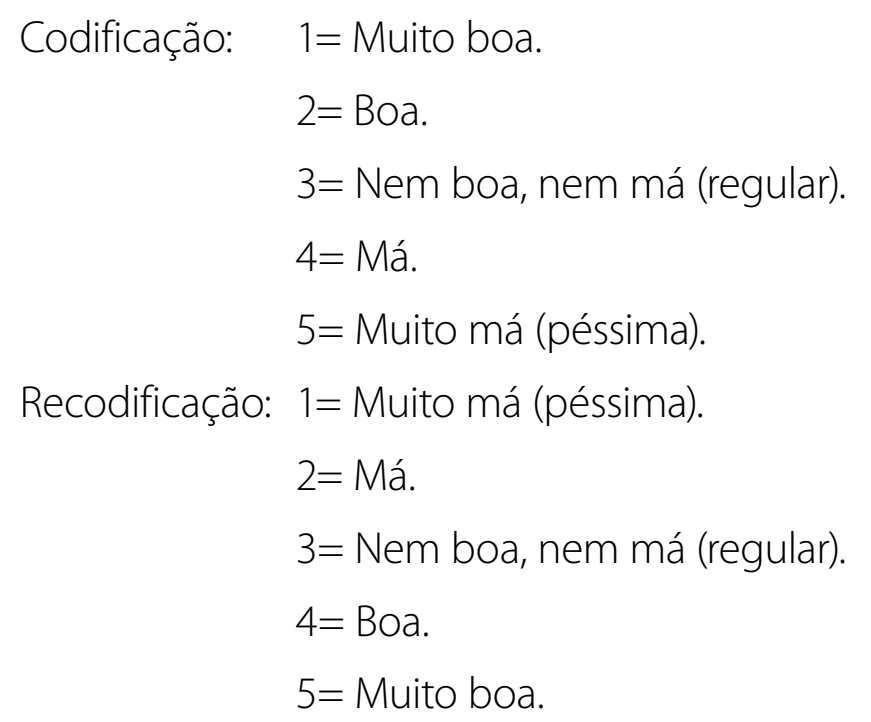

O índice corresponde ao somatório das variáveis.

Recebido: 3/09/2014

Aceito: 4/12/2014 